\title{
Desenhos de uma casa
}

\section{Angelo Bucci*}

Resumo O presente artigo se permite uma leve transgressão: falar de desenhos sem exibi-los. Propõe-se mostrar-lhes uma única obra, "Casa de fim de semana em São Paulo" ${ }^{1}$, pois através dela pode-se thes fazer inferir os desenhos que permitiram pensá-la em projeto. É uma espécie de filtro, de prova do valor efetivo do desenho aplicado ao projeto nas suas diversas formas e nas sucessivas fases, isto é, se nessa "visita" à obra e suas razões os desenhos não afloram, é porque eles não eram necessários ao processo. Enfim, os desenhos, aqueles que realmente contam para o processo de projeto e obra, permanecem impressos na própria obra.

Palavras-chave: desenho, processo de projeto, habitação.

\section{Dibujos de una casa}

Resumen Este artículo se permite una ligera transgresión: hablar de los dibujos sin exponerlos. Proponemos mostrar sólo una obra, "Casa de fin de semana en São Paulo", porque a través de ella se pueden inferir los dibujos que permitieron pensar en ella como proyecto. Es una especie de filtro, una prueba del valor efectivo del dibujo aplicado al proyecto en sus diversas formas y fases sucesivas, es decir, si en esta "visita" a la obra y sus motivos no surgen los dibujos, es porque no eran necesarios para el proceso. En definitiva, los dibujos, los que realmente cuentan para el proceso de diseño y construcción, quedan impresos en la propia obra.

Palabras clave: dibujo, proceso del proyecto, vivienda.

\section{Drawings of a house}

Abstract The present article allows itself a slight transgression: to talk about drawings without showing them. It is proposed to show only one work, "Weekend House in São Paulo", because through it, it is possible to infer the drawings that allowed us to think of it as a project. It is a kind of filter, a proof of the effective value of drawing applied to the project in its various forms and successive phases, that is, if in this "visit" to the work and its reasons the drawings do not emerge, it is because they were not necessary to the process. In the end, the drawings, those that really count for the process of project and work, remain printed in the work itself.

Key words: drawing, project process, housing. 


\section{desenho que busca razões e o desenho que encontra
representações}

Antes de iniciar, será feito um comentário oportuno sobre exigência da prova de aptidão nas escolas de arquitetura. A ideia de um desenho supostamente pré-requisito para alguém que almeje iniciar na atividade da arquitetura. $O$ exame consiste basicamente numa prova normalmente dividida em três modalidades de desenho: memória, observação e criação. O intuito seria medir a capacidade de se expressar graficamente e, paralelemente, a aptidão de um candidato à carreira de arquiteto.

Para comentar o tema, relato um pouco da minha própria experiência como candidato em duas oportunidades, nos exames vestibulares para a FAUUSP em 1982 e 1983. Claro, eu sabia da existência daquele exame. Fiz, com toda ingenuidade, a prova de aptidão na minha primeira tentativa de ingresso na faculdade de arquitetura e fracassei naquela prova e, consequentemente, no vestibular. Depois disso, fiz um ano de curso preparatório para o vestibular, no qual se oferecia um curso de desenho tendo em vista aquela prova. Tive dois excelentes professores, os irmãos Tom e Wilis Miyasaka. Fiz os exames pela segunda vez e fui muito bem classificado naquela prova decisiva, então tive sucesso no vestibular. Devo isso, sem dúvida, aos meus dois professores.

No entanto nunca me iludi que aprendera a desenhar em trinta aulas. Era claro para mim, isso sim, que naquele meu segundo vestibular eu soubesse melhor sobre o que estava sendo pedido e que, além disso, eu tivesse mais recursos para responder dentro daquilo que se esperava como resposta. Desenho de criação que pressupõe uma resposta padrão? Sim. E há razões para isso. Mas, ao mesmo tempo, nota-se o procedimento: perguntas que não querem saber; elas, acima de tudo, apenas se querem confirmar. Com efeito, praticamente todas as questões num exame vestibular são assim e, é fato, não poderia ser muito diferente. Em todo caso, é interessante notar que a essa maneira de proceder corresponde um modo de desenhar. Ambos, digamos assim, cristalizados como um saber institucionalizado.

A questão que se sobressai para mim hoje é que não creio ser esse o modo mais interessante de se proceder ou desenhar, quando se faz um projeto.

Então me pergunto sobre a validade daquela prova. Há outro aspecto que soma razão para esse questionamento. O quanto aquele domínio prévio colabora [como recurso] ou distrai [porque camufla o principal] no processo de iniciação em arquitetura e de elaboração de um projeto. Além disso, por outro lado, é visível que a prática da

* Angelo Bucci é Arquiteto e Urbanista, Professor da Faculdade de Arquitetura e Urbanismo da Universidade de São Paulo, ORCID <https://orcid.org/00000003-3316-4637>. arquitetura vai nos fazendo mais aptos a usar o desenho como um modo de pensar fluente e afeito à uma determinada abordagem e interesses específicos de cada um. Acredito que uma 'aptidão' para o desenho construída ao longo da prática contínua pressupõe engajamento e vitalidade; e, assim, ela caminha junto com a construção 
1 Projeto desenvolvido pelo escritório SPBR entre 2010 e 2011 e com construção entre 2013 e 2014. Sobre a crítica ao projeto ver: PERROTTA-BOSCH, 2014; SPBR ARQUITETOS, 2011; SPBR ARQUITETOS, 2014. de um pensamento crítico sobre a atividade que tende a assegurar uma prerrogativa de validade. É algo que não se alcança de outro modo. O domínio prévio colabora nesta construção?

Bem, talvez eu tenha feito esses parênteses apenas para declarar: não sou um desenhista talentoso. Ao mesmo tempo, não sinto nenhum bloqueio na matéria para o exercício do que faço. Mas, sinceramente e talvez por sorte, nunca tive desenhos bonitos, por assim dizer, a ponto de me deixar seduzir por eles. Digo apenas com declaração, não como uma opinião. No meu caso, na prática da atividade desde a escola, o desenho veio junto com outros recursos como a maquete ou os textos; sem que eu pudesse prescindir de qualquer um deles, sem que eu possa dizer qual deles teve maior importância no processo. Hoje considero uma sorte o fato de que eu não dominasse o 'desenho' com suficiente talento. Afinal, tantas vezes é justamente uma falta o que nos abre caminhos. Ou talvez porque, às vezes, o que se busca num projeto são razões antes que representações.

\section{O desenho como escritura e o desenho como esferas de diálogo}

Importa considerar o processo, ou o modo como se trabalha e como se dialoga num pequeno escritório de arquitetura. Os esboços são imprescindíveis nesse processo. A razão é simples, eles correspondem à fluência da fala ou, melhor dizendo, à fluência do pensamento ponderado. Com efeito, são os esboços que, invariavelmente, acompanham as primeiras conversas sobre um projeto. É, portanto, através deles que se lança as primeiras hipóteses, as declarações iniciais de como enfrentar uma dada questão.

Além dos esboços feitos à mesa, a lousa também é um recurso importante, porque nela um esboço perdura, permanece à vista de todos durante o processo de desenvolvimento do projeto. Ali, o esboço é vivo, pois pode ser alterado, ou acumulado, durante o processo. A permanência visual de um esboço chave para a premissa inicial evita que se percam aquelas razões à medida que se mergulha em cada pormenor.

Ao longo do processo de desenvolvimento de um projeto, os desenhos correspondem a um modo particular de registro ou 'escrita'. A eficiência dessa escrita é de simples comprovação: basta ver como qualquer arquiteto ao final do processo descreve todo o percurso de um projeto 'lendo' apenas desenhos, ele lê ali cada argumento, reconhece naquela configuração a participação de cada interlocutor que tomou parte do processo. Nesse sentido, desenho é escritura.

Outro aspecto que merece ser destacado diz respeito às esferas de diálogos que a elaboração de um projeto pressupõe. São elas que definem em última instância as chamadas fases de projeto. E, muito importante, cada uma delas exige um modo próprio de se desenhar.

A primeira fase se caracteriza por uma primeira esfera de diálogo bastante restrita, na qual os interlocutores se limitam, em geral, a dois: arquiteto e sujeito que lhe faz a demanda. A esta primeira fase denominamos estudo preliminar, à qual corresponde um modo muito próprio de se desenhar onde o partido, o programa e a disposição espacial estejam suficientemente representados. 
2 Sobre a discussão sobre a cidade de São Paulo ver: $\mathrm{BUCCl}$, 2010.
Após o acordo construído nessa primeira esfera, passa-se à segunda, é quando entram em cena novos interlocutores. Eles são, via de regra, engenheiro estrutural, engenheiro de instalações, arquiteto paisagista, enfim, todos aqueles que respondem pelos ditos projetos complementares. A essa segunda esfera se denomina anteprojeto e a ela também corresponde uma forma própria de se desenhar, com o necessário rigor técnico para amparar adequadamente esse nível de interlocução.

Outra vez, construído esse segundo patamar de acordo, produto do anteprojeto, abre-se uma terceira esfera de diálogo, que mantém normalmente os mesmos interlocutores, mas que pautam seu diálogo noutro patamar de entendimento, consolidando as construções comuns no processo. A essa terceira fase do processo denomina-se projeto executivo.

As fases, as esferas de diálogo e os desenhos correspondentes a cada uma delas são sucessivas. De modo que não há modo de alcançar a fase subsequente sem que entrem em cena os interlocutores necessários a cada fase precedente e que marcam cada esfera de diálogo. Não há redução, ou simplificação, possível. O formato dos desenhos é adequado a cada esfera, e também eles não admitem simplificações. Os desenhos são o nosso modo de dialogar nesse processo e são, ao mesmo tempo, produto dele. Por isso, os desenhos são, ao mesmo tempo, meio e fim no processo.

\section{O desenho dos conteúdos e o desenho dos continentes}

Como se desenha o ar? Como se desenha a água? Ou, perguntando de outro modo, como se define ar ou água? Como se define a superfície na cidade de São Paulo?² A premissa que interessa nesse caso é que para definir superfície, é preciso definir o elemento ao qual a superfície se relaciona: terreno, lençol freático, camada de solo firme, galerias de água, fios elétricos, copa das árvores, rotas aéreas e assim por diante. São superfícies sobrepostas. Voltaremos a isso a seguir.

Nesta foto aérea (Figura 1) se vê um pequeno trecho da cidade de São Paulo para mostrar a área e o entorno da obra que será analisada.

A linha que se destaca é o rio Pinheiros $O$ que se vê na imagem é um canal construído, o rio contido no seu leito retificado. Já não é tão fácil inferir aqui aquele seu antigo leito natural e sinuoso, que ocupava uma área de várzea muito maior dos 70 metros de largura do canal que se vê nesta foto aérea. Assim, para saber, por exemplo, qual o desenho do rio Pinheiros deve-se definir antes em que momento histórico ou em que época do ano. A própria área, onde está o terreno deste projeto, pertencia originalmente ao domínio do rio. Se pretender entender um simples lote que constitui a base onde se vai intervir, ou desenhar, se começa a ver que esses desenhos, história, estão impressos ali em alguma medida. Não se escapa de dialogar, em primeiro lugar, com uma precedência, com a geomorfologia. Junto ao rio se vê as avenidas marginais e a ferrovia. A avenida paralela ao rio que se destaca é a Faria Lima. Esse feixe de infraestruturas dão a escala nitidamente metropolitana do lugar.

Em contraste se vê que o lote em questão está inserido numa espécie de ilha urbana formada por construções de pequeno porte circunscritas num perímetro definido 


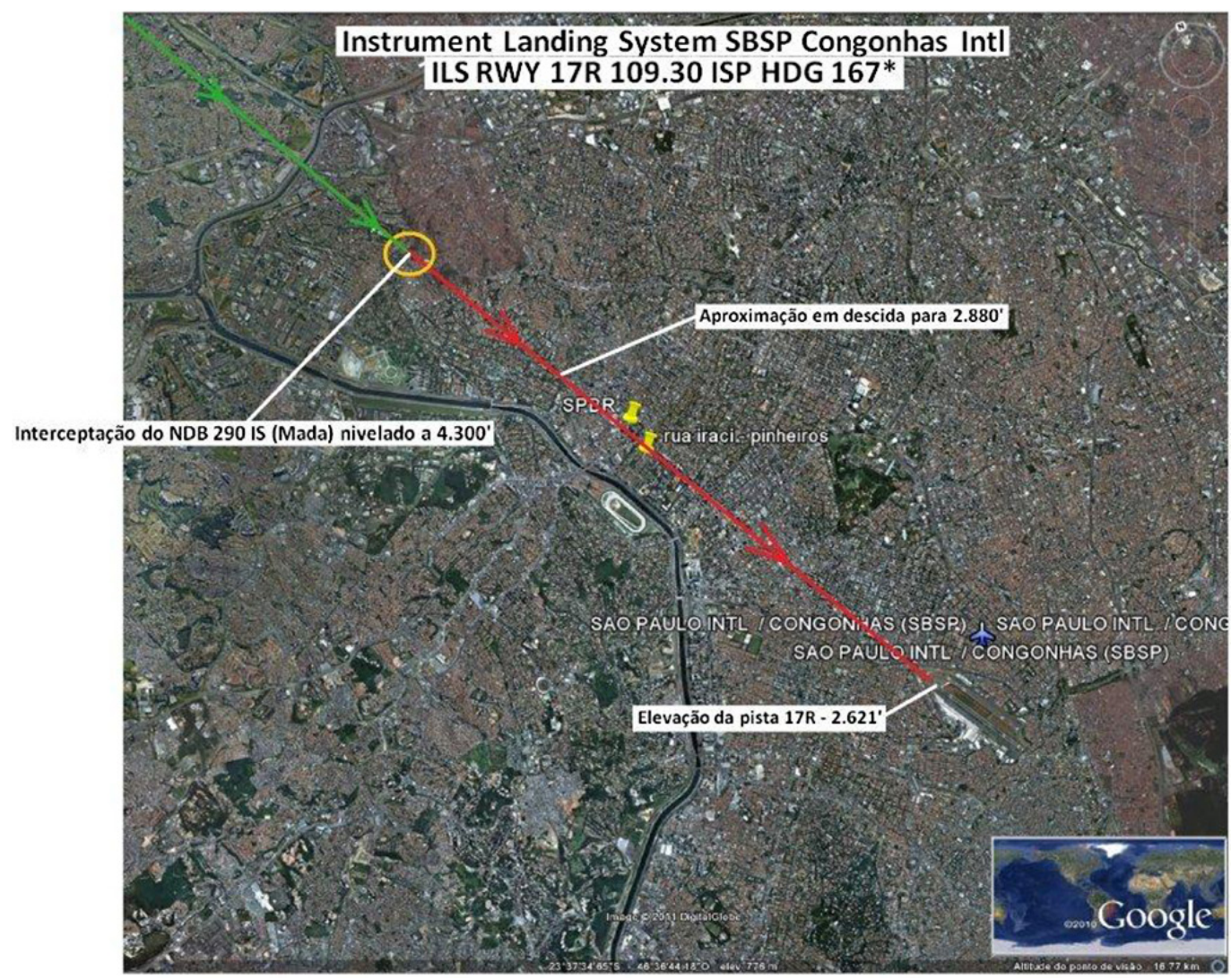

Figura 1: Aerofoto, com o local do projeto assinalado em vermeIho. Fonte: google earth. por arranha-céus. É um desenho que resulta da norma, pois a legislação restringiu em seis metros o gabarito de altura das edificações naquele trecho.

O contraste entre a escala daquelas pequenas construções e da escala metropolitana tem grande interesse para este projeto.

Há ainda um outro eixo de infraestrutura destacadamente metropolitano que passa por aí. Ele também está paralelo ao rio, mas passa a $800 \mathrm{~m}$ acima do nível do solo. É a rota dos aviões (Figura 2). Que pode ser representada simplesmente pela linha da sua projeção sobre a planta da cidade, com as anotações indicativas da altura acima do nível do solo em cada trecho. A cada padrão de altura pode-se fazer corresponder uma cor. Em projeção, achata-se as distintas 'superfícies' num único plano. Para garantir a aproximação dos aviões ao aeroporto com a devida clareza e segurança de orientação é necessário um desenho técnico, onde a rota é traçada com todas as instruções geométricas necessárias e precisa para a rota aérea. Nesse caso, o desenho corresponde a um projeto de voo. Pode-se dizer que o terreno de implantação deste projeto está localizado oitocentos metros abaixo da superfície da rota aérea naquele trecho já no cone de aproximação para o aeroporto de Congonhas. 
ILS RWY 17R HOTEL ,

\begin{tabular}{|l|l|l|}
\hline $50 \cdot 1$ & 15 JUN 11 \\
\hline
\end{tabular}

Brazil - SBSP / CGH

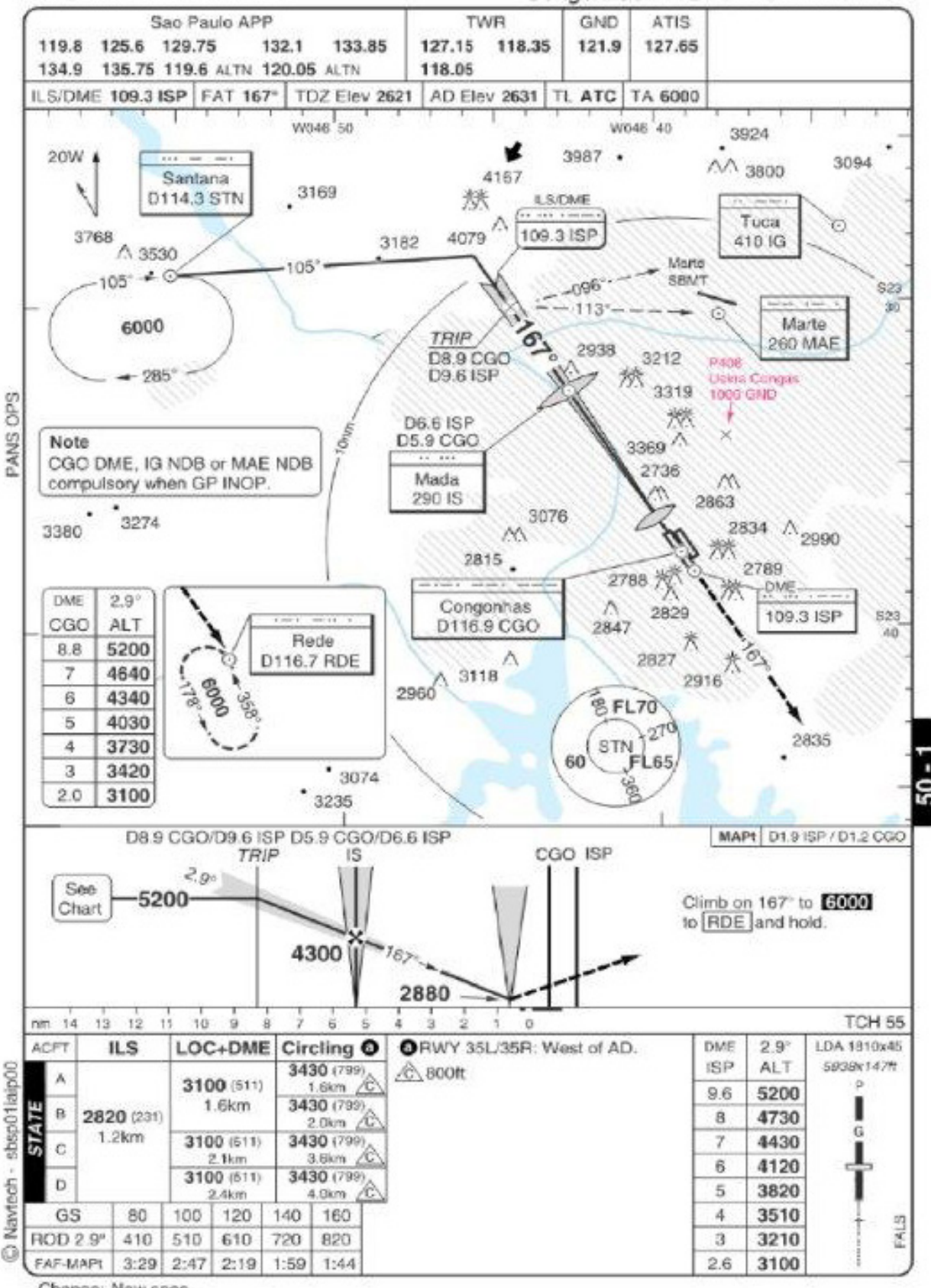

Figura 2: Plano de voo. Fonte: COMAER. 


\section{O desenho difuso da demanda, ou do desejo}

A demanda para um projeto como este nasce de um desejo difuso pois ele ainda não encontra correspondência num objeto concreto. Nesse caso, o desejo ensejado no repertório rico do convívio entre um filósofo, especialista em Montaigne, é uma ilustre consultora de moda, que diz que 'chique é ser civilizado' e percebe-se que ela alinha perfeitamente a sua atividade ao que norteia a atividade do escritório em arquitetura. Enfim, os dois juntos significam a oportunidade de uma interlocução privilegiada para a arquitetura.

Eles vivem em seus apartamentos na cidade de São Paulo, querem permanecer ali, mas armaram esse plano de construir naquele lote uma piscina e um jardim e extensões deste programa principal, pois queriam ter como um destino para os seus finais de semana um endereço dentro de São Paulo.

Movidos por aquele desejo, eles produziram um desenho (Figura 3), um primeiro plano claro do programa que pretendiam construir: piscina, jardins, um pequeno apartamento para caseiro, um pequeno apartamento eventual para o casal e uma área para reunir os amigos. É esse o desenho que trouxeram em nossa primeira reunião.

Pode-se dizer que, dentro de certos limites, a função de um arquiteto não é ter ideias e sim saber como se constrói as coisas. Explico, as ideias [que afloram de um desejo difuso] carecem de especificidade para se configurar como um projeto. A ideia não basta para delinear nitidamente o objeto, ou o edifício, que ela requer. A maior especialidade da arquitetura talvez seja a de dar morada, ou permanência, às ideias. Pois é só quando o desejo encontra, através desta especificidade, o objeto que the corresponde, que a própria ideia resiste.

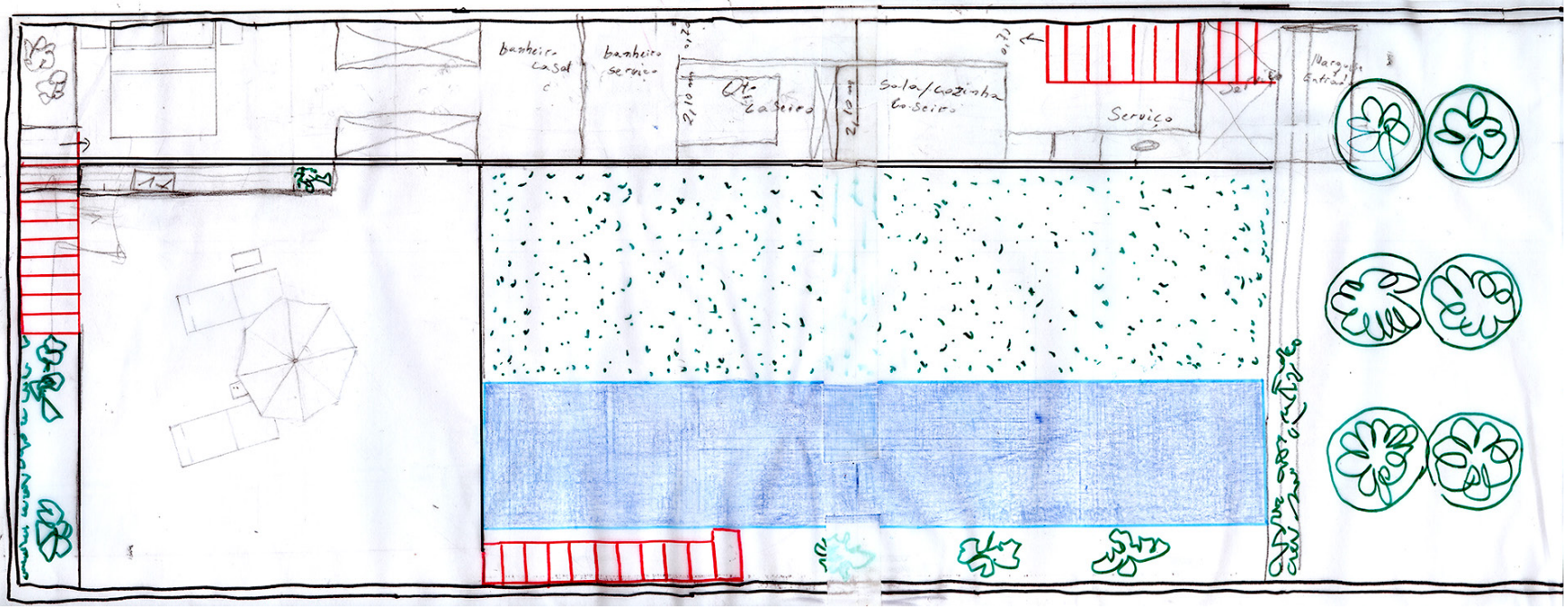




\section{O desenho do contra fluxo e o desenho do que não tem nome}

Um primeiro ponto que atraiu naquela demanda foi o fato de ser um projeto no contra fluxo. Ficar em São Paulo em vez de passar o final de semana preso naquele tráfego que viaja nos finais de semana com boa parte da cidade pelas estradas à praia ou ao interior. O programa era, portanto, como uma casa de veraneio dentro da cidade. Então, em primeiro lugar, tinha um sentido de contra fluxo no sentido de tráfego. Além disso, um contra fluxo também como ação construtiva. Quero dizer, em vez de se pretender o máximo coeficiente de aproveitamento, buscavase ali justamente o contrário, a meta era atingir a máxima área permeável, a maior superfície de jardim.

Outro aspecto bastante atraente era o fato de que não se sabia exatamente como denominar aquele programa. Como desenhar o que não se sabe o nome? Piscina era uma denominação insuficiente. Casa de fim de semana, também não correspondia precisamente ao programa. Enfim, o programa não tinha um nome exato e agradava porque era necessário definir ou redefinir ali os elementos principais do programa. Mais que isso, os elementos do programa que aqui eram a essência, piscina e jardim, são tipicamente peças acessórias do programa mais essencial em arquitetura, a casa. Então, vem a questão: como é possível subtrair de um programa a sua essência e garantir que o que remanesce não desvaneça numa melancolia profunda? Isto é, fazer a piscina e o jardim de uma casa que não estava lá não seria uma resposta adequada. Nesse sentido, era preciso, em alguma medida, redefinir o estatuto desses dois elementos, normalmente acessórios, para que eles pudessem figurar como protagonistas daquela cena arquitetônica.

\section{O desenho da arquitetura [configuração concreta do objeto]}

Então, começa o diálogo.

Seis metros é o gabarito, não há recuo lateral. A construção vizinha do lado leste tem seis metros de altura, a oeste, a mesma coisa, ambas coladas na divisa. Uma faz sombra a manhã toda, a outra a tarde inteira. Por isso, se eles já tinham esboçado um plano inicial suficientemente claro de programa, por outro lado já haviam formulado uma preocupação que lhe correspondia com a mesma objetividade: a piscina não teria sol suficiente.

Por isso, trouxeram a pergunta pronta: "Devemos fazer a piscina mais a leste ou a oeste?" Então, foi exposto que o intervalo de sol não se alteraria, apenas os horários de incidência seriam diferentes numa situação e noutra. Mas, em seguida, foi comentado que deslocar a piscina era ótima ideia, mas não a leste nem a oeste, a saída era deslocá-la para cima em direção à luz do sol, à uma maior porção de céu visível. Então, perguntaram: "Quanto?". "Seis metros", foi a resposta. E eles: "Por quê?". Porque ali está a superfície, digo, para efeito da incidência direta do sol a superfície naquele terreno foi definida por lei a seis metros de altura. (Figura 4)

Foi assim que tudo começou. 
Figura 4: Corte transversal, com o perfil das edificações vizinhas. Fonte: SPBR, 2011.

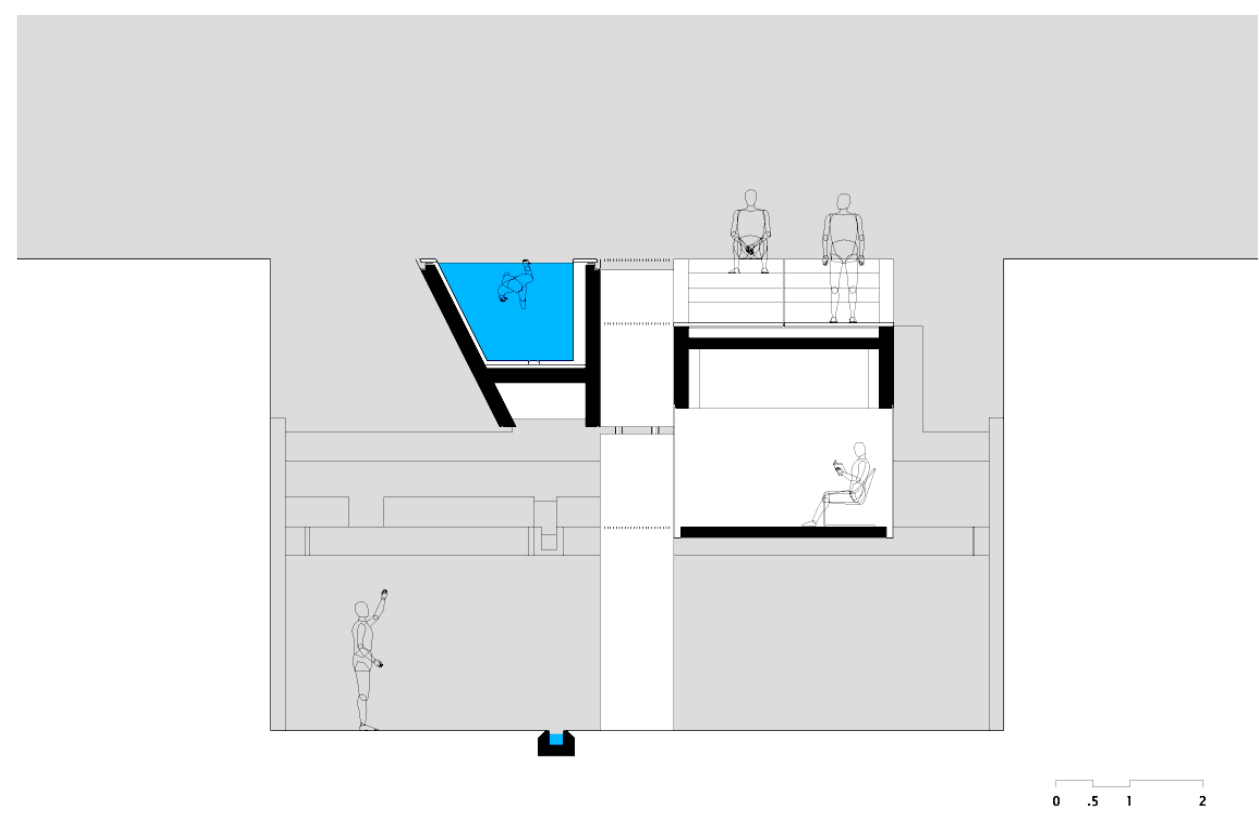

A comparação entre a planta do que foi construído com aquela que eles apresentaram na primeira reunião, mostra que se trabalhou com fidelidade àquele esboço que chegou pronto. Mas, claro, é na elaboração que aquele esboço e o projeto que se desdobra a partir dali se distinguem. A distinção está no arranjo construtivo e, sobretudo, no arranjo espacial, com destaque para o seu desenvolvimento vertical. O que dá o caráter da abordagem do projeto elaborado é o modo de se compreender o problema e o lugar. Nesse caso, a compreensão aflora da consideração das camadas sucessivas de superfícies sobrepostas. É isso que permite imaginar uma organização do programa disposto em três camadas distintas, sendo que a cada uma delas corresponde uma condição própria de ambiência e relação com o entorno. (Figura 5)

O tanque elevado de seis metros e o jardim dominando o nível do chão. Melhor dizendo, o tanque principalmente elevado e o jardim principalmente no chão. De todo modo, se por um lado interessava elevar a piscina, também era interessante minimizar a sombra projetada pois interessava fazer chegar o máximo de luz ao chão. Por isso, a raia está disposta no sentido norte-sul, portanto de nascente a poente o sol varre toda a extensão do solo. Outro corpo paralelo àquele era necessário para fazer um solário também elevado. Entre um e outro, um vazio (Figura 6). Assim, estas duas peças funcionam como uma pérgula gigante, que permite muita luz chegando ao nível do terreno. É também para favorecer a entrada de luz que a parede oeste da piscina se inclina, do mesmo modo é por isso que a escada que leva à cota da piscina e solário é tão vazada à luz. O tanque da piscina se enche de água, é uma carga. De modo similar, o solário se carrega com os apartamentos sob a projeção para não aumentar a área de projeção de sombras no jardim. Assim, piscina e solário se equilibram como elementos do programa e, mais importante do que isso, se equilibram também como carga e estruturalmente: um é contrapeso do outro. Dois pilares, dispostos exatamente sob o vazio entre as duas peças, sustentam o conjunto. 

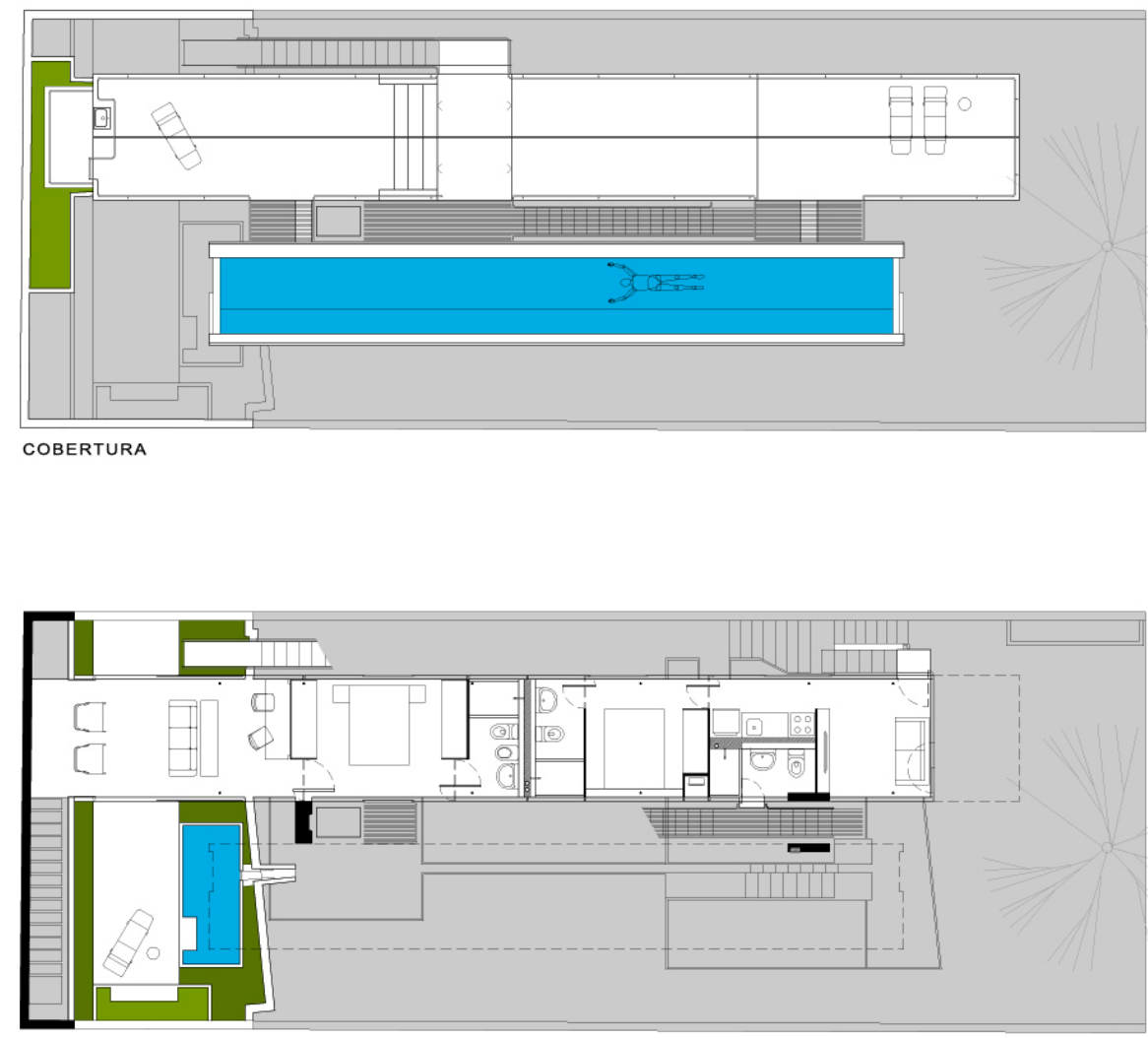

PAVIMENTO SUPERIOR

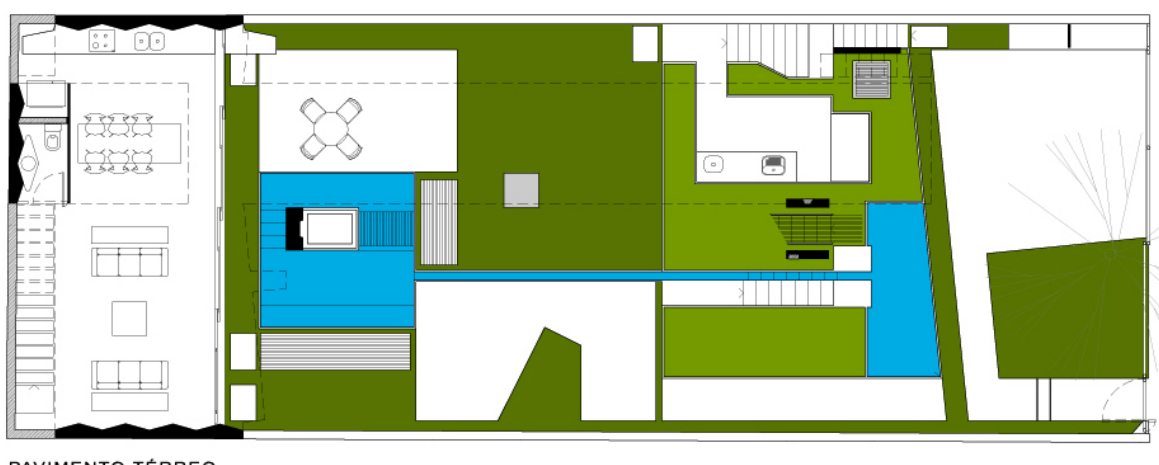

PAVIMENTO TÉRREO

Figura 5: Plantas. Fonte: SPBR

2011.

rISCO. v19_2021 - Edição Temática "Desenho" 
Figura 6: Fotografia da maquete, mostrando o perfil longitudinal do projeto. Fonte: foto - Nelson Kon, 2011; maquete - SPBR / Nilton Suenaga, 2011.

Figura 7: Fotografia da entrada. Fonte: Nelson Kon, 2013.
Apesar da piscina elevada, a casa de máquinas foi disposta junto ao solo, semi-enterrada. O caminho da água entre uma coisa e outra se faz por vertedouros e outros três tanques menores. Do mesmo modo, o jardim se eleva por dispositivos de caixas de terra elevada ou grelha de suporte junto às laterais. Assim, a piscina se mescla com o jardim e os dois elementos se esparramam verticalmente fazendo-se presentes nos três níveis, ou camadas, em que o edifício se desenvolve.

Tudo o mais se desdobra a partir dessas considerações. No mais é o que se vê, os desenhos, aqueles que de fato contam, devem ser encontrados impressos na obra (Figura 7).
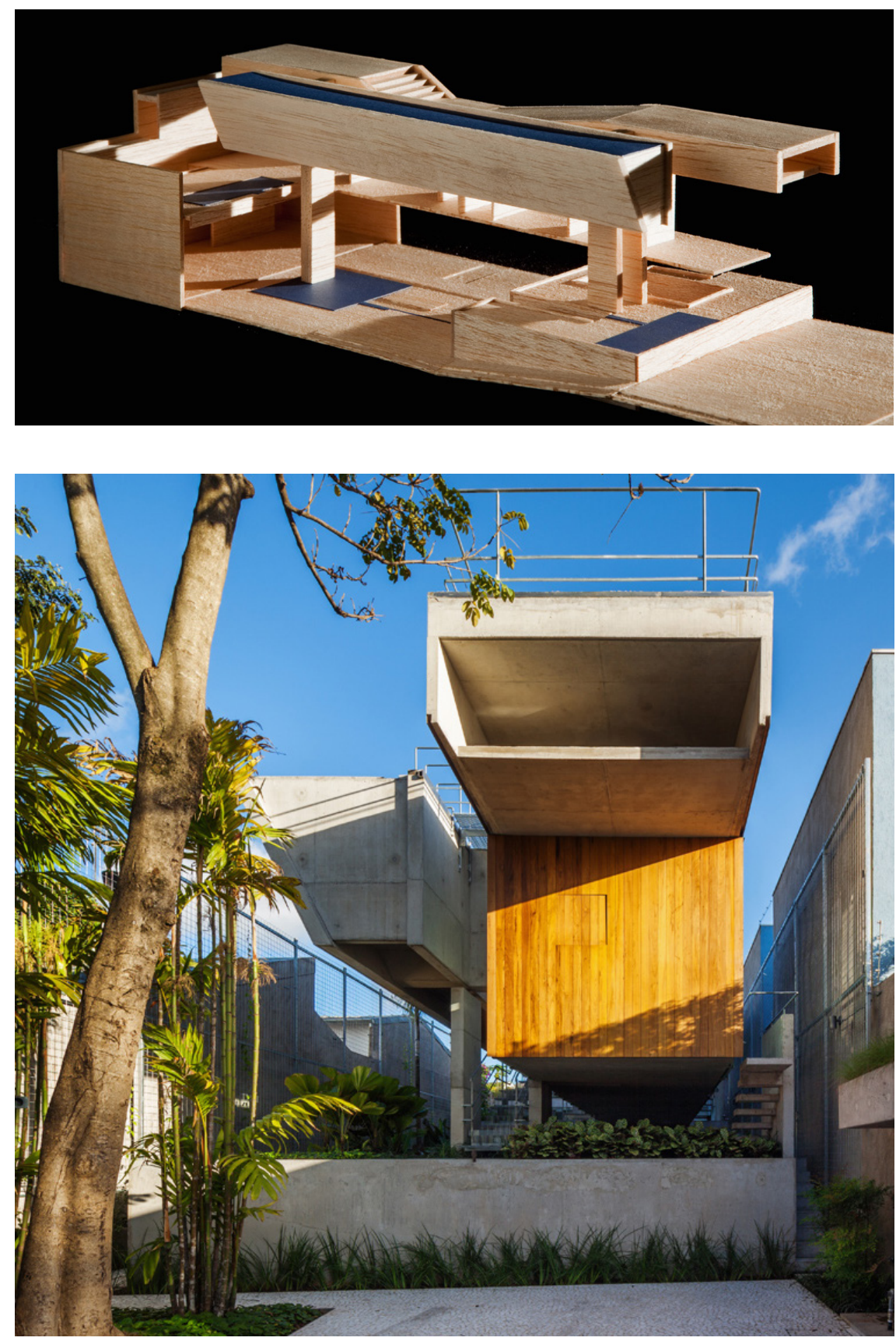
Figura 8: Fotografia da piscina. Fonte: Nelson Kon, 2013.

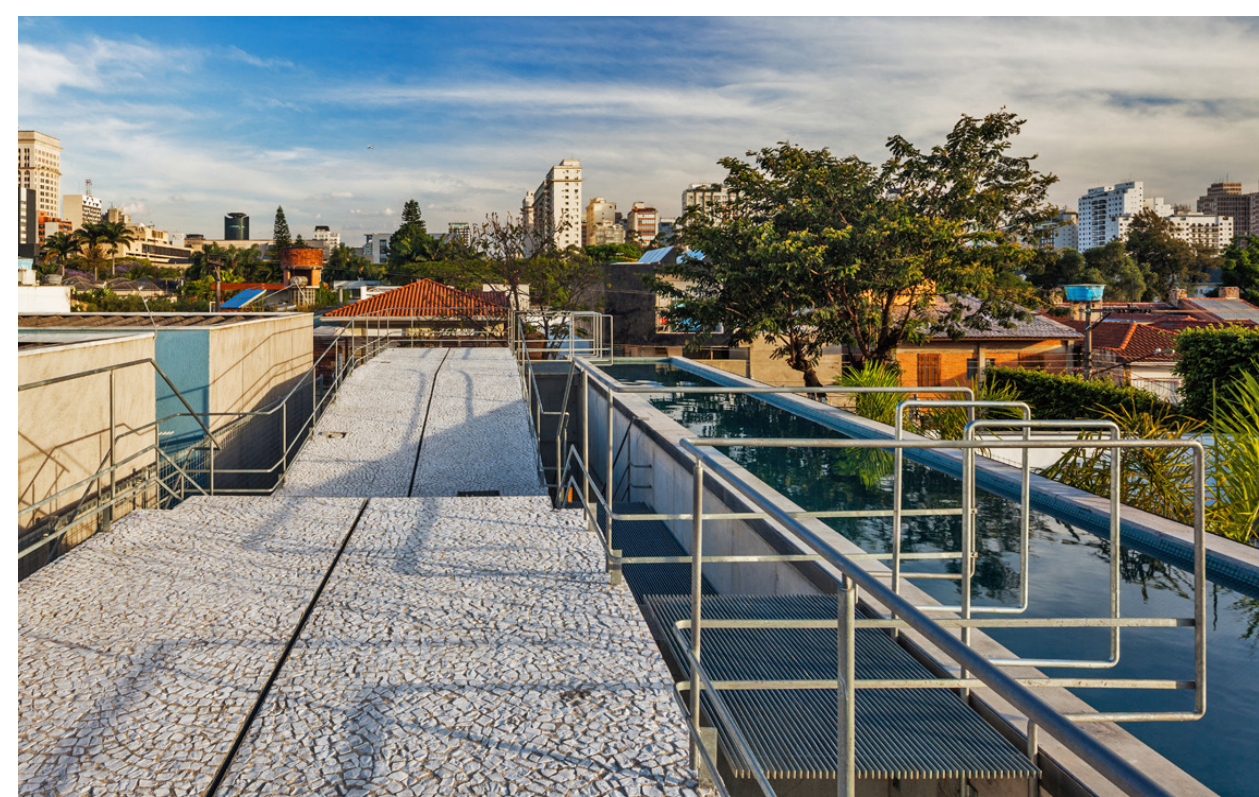

\section{O desenho das imagens, o processo da imaginação}

Como se imagina um projeto assim? A imaginação coloca em ação imagens que se trazem no acervo imaginário. Esse acervo é composto por elementos, fragmentos, palavras; a cada elemento corresponde uma configuração típica que foi introjetada. São as respostas automáticas, inevitáveis. Essas respostas são valiosas porque insere a todos num grupo e permite conversar e alcançar um bom nível de entendimento; mas são também perigosas porque impõe um limite muitas vezes indesejável que pode impedir de se considerar alternativas. Para ser mais claro, exemplifico. Quando se pede: desenhe uma piscina. Começa-se, automaticamente, a cavar o chão; pois é assim que se faz uma piscina. Por isso soa tão estranho uma piscina a seis metros de altura. Porém, quando se pede: desenhe uma caixa d'água. A resposta que vem é de um volume d'água elevado do solo, pois aqui a carga hidráulica é a condição crucial. Piscina ou caixa d'água são dois elementos corriqueiros. A primeira sempre afogada no solo ou a segunda sempre elevada. As duas coisas são comumente construídas no contexto como um tanque em concreto armado. Isto é, a cada uma dessas duas palavras há uma construção típica que the corresponde e que se opõem quando vistas em seção vertical. Mas, por outro lado, como fato elas são a mesma coisa: dois tanques cheios d'água (Figura 8). Então, em vez de dizer eleve-se a piscina, é proposto: Vamos nadar na caixa d'água!

\section{Referências bibliográficas}

BUCCl, Angelo. São Paulo, razões de arquitetura: da dissolução dos edifícios e de como atravessar paredes. São Paulo: Romano Guerra, 2010.

SPBR ARQUITETOS. Weekend house in downtown São Paulo. In: GA houses. Project 2011. n 120. Tokio, Japão: A.D.A EDITA Tokyo, 2011

SPBR ARQUITETOS. A swimming pool in São Paulo. In: GA houses. Special Feature: House in Sao Paulo 1. n 135. Tokio, Japão: A.D.A EDITA Tokyo, 2014

PERROTTA-BOSCH, Francesco. É uma piscina. É um jardim. In: Projeto Design. n ${ }^{\circ 07}$. São Paulo: Arco, 2014. 